This is an Author's Accepted Manuscript of an article published as:

Andrew Hamilton, Ben Waterson, Tom Cherrett, Andrew Robinson \& Ian Snell (2013), The Evolution of Urban Traffic Control: Changing Policy and Technology,

Transportation Planning and Technology, 36(1), pp 24-43.

The definitive version is available at: http://dx.doi.org/10.1080/03081060.2012.745318

\title{
The Evolution of Urban Traffic Control: Changing Policy and
}

\section{Technology}

\author{
Andrew Hamilton ${ }^{1}$, Ben Waterson ${ }^{1}$, Tom Cherrett ${ }^{1}$, Andrew Robinson ${ }^{2}$, \\ Ian Snell ${ }^{2}$ \\ ${ }^{1}$ Transportation Research Group, University of Southampton, Southampton, UK \\ ${ }^{2}$ Siemens, Poole, $U K$
}

The history of urban traffic control (UTC) throughout the past century has been a continued race to keep pace with ever more complex policy objectives and consistently increasing vehicle demand. Many benefits can be observed from an efficient urban traffic control system, such as reduced congestion, increased economic efficiency and improved road safety and air quality.

There have been significant advances in vehicle detection and communications technologies which have enabled a series of step changes in the capabilities of UTC systems, from early (fixed time) signal plans to modern integrated systems. A variety of UTC systems have been implemented throughout the world, each with individual strengths and weaknesses; this paper seeks to compare the leading commercial systems (and some less well known systems) to highlight the key characteristics and differences before assessing whether the current UTC systems are capable of meeting modern transport policy obligations and desires.

This paper then moves on to consider current and future transport policy and the technological landscape in which UTC will need to operate over the coming decades, where technological advancements are expected to move UTC from an era of limited data availability to an era of data abundance.

Keywords: urban traffic control; technology; policy; congestion 


\section{$1 \quad$ Introduction}

Over the past 60 years, motor vehicle miles have increased by approximately $1000 \%$ in the UK (DfT, 2010), with a similar trend worldwide (e.g. in the USA vehicle miles travelled has grown by nearly 500\% since 1940 (US Census Bureau, 2005)). With more vehicles on the road, the need for controlling the flow in an urban environment has become increasingly important to maximise safety and capacity, and minimise both the time loss and environmental impacts of congestion.

Since the earliest days of gas powered traffic lights (Day and McNeil, 1996), urban traffic control has evolved with three key influencing factors: increasing numbers of vehicles on the road network, advances in (and limitations of) technology and the desires of policy makers to maximise sustainable mobility .

This paper aims to show that at any point in time the leading UTC systems are defined by the capabilities of the available technology, and hence UTC systems have historically had to wait for technological advances to facilitate step changes in performance. A new phase is beginning where technological advances are faster than the development rate of UTC systems, causing a rebalancing of the relationship between policy, technology and UTC systems.

\section{The Past}

\subsection{PHASE 1 - Origins of Traffic Lights [1868 - 1920]}

The original gas powered traffic light was based on railway designs and had only two colours, red and green. The signals were manually operated by police officers and their purpose was to improve visibility of the traffic controller as the mast was 24 feet high and could be seen on all arms of the junction (The Engineer, 1868). However the problem with this system was that it was severely limited by the technology as police officers were still required at the junction because there was no automatic control. Unfortunately the first UK traffic signals did not last long in operation, as they exploded less than a month after installation (BBC, 2009).

The subsequent electric powered traffic light was first introduced in the UK during the 1920s after observing its success in America and Germany. There were a number of policy objectives behind the introduction of traffic signals; primarily they were developed to relieve police officers of traffic management duties as traffic growth was rapidly increasing and many more police officers were required to direct traffic flow. This is the first example of policy driving the development of traffic signals; firstly, the members of parliament reasoned that there would be some improvement to public safety. And secondly, there was a substantial financial benefit as the installation costs were approximately $£ 100$ whereas a week's wages for a police officer was $£ 6$ to $£ 7$ and therefore the local authorities would see a rapid return on their investment (Royal Commission on Transport, 1929). 


\subsection{PHASE 2 - 'Fixed Time Plans' [circa 1920 - 1980]}

This phase saw the real beginnings of UTC as rising congestion led to increased awareness of the issues amongst policy makers and consequently defined the basic objectives for all UTC systems. Congestion was highlighted as a serious issue for the United Kingdom from as early as 1964 by the Buchanan Report, when he predicted up to 40 million vehicles in the UK by 2010 (Buchanan, 1964); in 2009 there were over 34 million registered vehicles (DfT, 2012). The Buchanan Report did encourage the government to seek alternatives to private vehicles; and in 1969 the UK policy highlighted that building evermore roads was not the solution to urban congestion (Ministry of Transport, 1969). Whereas in 1952, President Eisenhower stated a grand plan for the US to reduce metropolitan congestion by building a properly articulated highway system (Connery and Leach, 1960), this shows the different approaches taken to manage congestion in the 1950s and 1960s. In both cases however, it was still policy objectives leading the way with traffic control systems trying to match the desired outcomes.

During the late 1950s, proposals were being made to improve the original isolated fixed time plans by co-ordinating traffic signals. This involved determining offset times between neighbouring junctions so that a 'green wave' could be created and therefore reduce delay and congestion along arterial routes (Papageorgiou et al., 2006). To enable this local co-ordination, junctions are typically defined into small regions where the signals can be optimised in terms of split, cycle and offset times. However for fixed time plans to synchronise correctly, the cycle times must be the same length or a direct multiple, and the regional cycle time is therefore typically defined by the busiest junction in the region.

The 'cycle time' is the total amount of time required to complete all phases at a junction. The 'split time' is the amount of allocated green time each phase has within a complete cycle. The 'offset time' is the time delay of green time between subsequent traffic signals to create smooth traffic flow. In its simplest form, the one-way offset time is the travel time between two junctions so that the downstream junction has a green light when the vehicles arrive (U.S. DoT, 2005). The offset time can be biased towards heavier traffic flow in one direction if required because the contra-flow can be insignificant in comparison (for example, morning rush hour into a city compared with flow out of the city).

Fixed time plans may be used to create green waves, give predetermined priorities, and respond to special events which can be predicted, such as football matches. However fixed time plans cannot respond to unplanned incidents such as traffic accidents or road works. Fixed time plans age rapidly, particularly where traffic growth is high, and the benefits of linking may be lost in three to four years if the plans are not updated regularly, which can be an expensive process (Papageorgiou et al., 2006). Studies have shown that fixed time plans degrade by approximately three percent each year, so it is imperative that plans are regularly updated (Bell and Bretherton, 1986).

When there are (predictable) high demand scenarios then fixed time signals are comparable to many coordinated UTC systems in terms of average delay but the duration of congestion is typically longer. However in light flow conditions, there is very little benefit to them as they could actually increase the delay to vehicles if the 
platoons frequently miss the allocated green time.

\subsubsection{TRAffic Network StudY Tool (TRANSYT)}

TRANSYT is one of the most well developed and widely used fixed time control design systems and is still in modern usage. It assumes that the flow is known and constant for a fixed period of time. TRANSYT calculates the timings off line, using historical, measured traffic data to generate optimum plans for the specific time of day, and day of the week. It is typically used at isolated junctions but can be used to coordinate sequential junctions (Gardner et al., 2009). TRL predicted and observed a fuel consumption reduction of three to five percent in Glasgow when TRANSYT was trialled to coordinate sequential junction (Robertson, 1982).

There are two main elements of TRANSYT; the traffic model and the signal optimiser. The traffic model represents traffic behaviour and predicts a Performance Index (PI) for a specific time plan and average set of flows on each link. The PI measures overall cost of traffic congestion, which is a weighted combination of total delay and the number of stops made by vehicles (Papageorgiou et al., 2006). Historical flow information correlated by the time of day is required by the model and a platoon dispersion model is applied to determine the offsets between junctions. The signal optimiser adjusts the signal timings in the model until the optimum PI is achieved. TRANSYT was shown to reduce journey time by 7.4 to $11.4 \%$ throughout the State of California compared with the original signal plans (Skabardonis, 2001).

\subsection{PHASE 3 - Vehicle Actuated (Isolated) Junctions [1970's - present]}

The ever growing problem of congestion was still at large, and the UK government sought after technological improvements during the 1960s. Funding was made available for research and development to individual authorities in order to find a solution to the problem; the government invested in schemes in London and Glasgow to improve the efficiency of the urban network (Ministry of Transport, 1966).

Inductive loops were developed and installed throughout the road network so that traffic signals could be triggered by vehicle presence at junctions. Isolated junctions are most commonly controlled using vehicle actuation in the UK (Gardner et al., 2009), and the most common detection method worldwide is inductive loops (Box and Waterson, 2010). The system is reliant on traffic detectors so that green times can be allocated accordingly; this inherently requires more infrastructure than fixed time signals so there is a higher initial capital required for vehicle actuated junctions, but there is substantial financial savings in vehicle hours and maintenance time. A large amount of time and resources is required to update fixed time plans, for example, Toronto estimated that it would take 30 person years of effort to update all of the fixed time signals before it decided to upgrade to a vehicle actuated system (Quan et al., 1993). .

Inductive loops are made up of coiled wire, which is embedded in the road, and a detector at the side of the road which powers the wires and creates a magnetic field around the loops. The loop resonates at a constant frequency which is monitored by the detector, and when a vehicle passes through the magnetic field, the resonant frequency increases and the detector becomes aware of a vehicle's presence (Marshproducts, 
2000). These loops are typically placed upstream of junctions so that a vehicle's presence is detected with sufficient time to react to change the traffic signals.

\subsubsection{Microprocessor Optimised Vehicle Actuation (MOVA)}

MOVA is an advanced vehicle actuated controller, it analyses lane by lane detector data and controls signal timing to minimise delay and stops. There are approximately 3000 junctions using MOVA throughout the UK, with an installation rate of over 200 junctions per year (TRL, 2011).

MOVA is designed to respond well to very low flows and oversaturated flows (TRL, 2011); before the junction becomes saturated, MOVA operates in a mode which minimises delay, but when the junction is saturated it operates in a maximum capacity mode. This is beneficial as no system can effectively deal with saturated conditions because there are simply too many vehicles on the road, so maximising capacity is a beneficial feature. Latest versions of MOVA are also capable of linking two or more junctions when they are not considered as isolated, for example, MOVA can be used in signalised roundabouts (TRL, 2011).

\section{The Present}

Inductive loops changed the way in which urban traffic control has operated; however isolated vehicle actuated junctions (e.g. MOVA) are not exploiting the full potential in an urban environment because there is no consideration of the effects on surrounding junctions. This section highlights the current potential of vehicle actuation through inductive loops, radar and infra-red detection technology, which are the main techniques used today, to coordinate neighbouring junctions.

Congestion is still identified as a growing economic problem, but is also considered as an environmental and social issue (Eddington, 2006). It has been estimated that congestion will be costing England at least $\$ 35$ billion ( $£ 22$ billion) in lost time per year (Eddington, 2006). According to Bloomberg, traffic congestion in the US in 2009 cost the economy $\$ 114.8$ billion ( $£ 72$ billion) (Bloomberg, 2011). While the underlying policy drivers are therefore still congestion and delay minimisation, the focus has increasingly become a more holistic view of people movement rather than individual trouble spots.

\subsection{PHASE 4 - Vehicle Actuated (Coordinated) Junctions [Late 1970s - Present]}

Vehicle actuated systems which have coordinated junctions are those most often referred to as Urban Traffic Control (UTC) systems. There are many different UTC systems globally; many theoretical UTC systems have been proposed but this paper will focus on those which have been adopted commercially and are used in many locations worldwide, see Table I. 
Table I: Number of UTC System Installations

\begin{tabular}{|l|l|}
\hline UTC System & \multicolumn{1}{|c|}{ Installations } \\
\hline SCOOT & More than 250 worldwide (TRL, 2011) \\
\hline SCATS & More than 20 worldwide (Jhaveri et al, 2003) \\
\hline UTOPIA & $\begin{array}{l}\text { Several cities in Italy, and also in Netherlands, } \\
\text { USA Norway, Finland and Denmark } \\
\text { (KonSULT, 2009) }\end{array}$ \\
\hline RHODES & 4 Installations (Jhaveri et al, 2003) \\
\hline MOTION & Installations in Germany (Mueck, 2008) \\
\hline
\end{tabular}

As with Phase 3, vehicle actuated systems for coordinated junctions use on-line detector measurements to optimise signal timings on a cycle to cycle basis to better meet demand. These systems can be coordinated from a central computer (e.g. SCOOT) or have distributed intelligence and be coordinated at a local level (e.g. UTOPIA). Centrally controlled systems use less complex local controllers; whereas decentralized systems take more local decisions, with some coordination between adjacent controllers (Papageorgiou et al., 2006).

All of the major UTC systems operate on a similar basis of adjusting the split, cycle and offset times to optimise the traffic flow through a series of junctions (Papageorgiou et al., 2006). However, each UTC system has a different algorithm for adjusting these variables to achieve a more efficient region or network of junctions.

An advantage of isolated vehicle actuated junctions compared with a coordinated system is that there is greater flexibility to change the traffic signals because there is no consideration of the subsequent effects on neighbouring junctions (Hounsell et al., 2001). However, if every traffic signal was to operate independently then the network as a whole could potentially suffer. A 'before and after' study was carried out in Virginia, which showed a reduction of $30 \%$ in journey time between the original uncoordinated, actuated junctions and the final coordinated actuated junctions (Byungkyu and Chen, 2010).

\subsubsection{Split Cycle Offset Optimization Technique (SCOOT)}

SCOOT is the most commonly used UTC system in the world (Table I) as it is installed in more than 250 towns and cities (TRL, 2011). It is a dynamic UTC system which uses live traffic data to determine a suitable signalling time. SCOOT typically uses inductive loop detectors at the upstream end of links to monitor cyclic flow profiles and measure demand in real time. SCOOT has three optimisation procedures to adjust signal timings: split, cycle and offset times, which are optimised at different frequencies and using different procedures (Papageorgiou et al., 2006). Some of the first studies of SCOOT showed that SCOOT can reduce delays by up $12 \%$ in comparison to an up-to-date fixed time plan system (Hunt et al., 1981); however more recent studies have shown that in comparison to a typical fixed time plan system, which isn't fully updated, SCOOT can reduce delays by up to $20 \%$ (Hounsell et al., 2001). 
SCOOT requires detection information very frequently to keep its plans updated, binary signals indicating the presence (or absence) of a vehicle are sent to SCOOT every second. SCOOT relies on the quality of input parameters to accurately model and react to vehicle behaviour (Wylie, 2009). The detectors can be used to identify accidents or congestion as the velocity of vehicles is known, and there is typically additional software used alongside SCOOT to best deal with these problems, for example Comet which provides a user friendly interface for the network operator. SCOOT makes a large number of small optimisation decisions, typically over 10,000 per hour in a network of 100 junctions (Hounsell et al., 2001), so there is a lot of information being processed.

SCOOT has flexibility in the system to override values and set parameters for different regions at different times, for example, gating strategies to protect an area from excessive traffic or bus priority measures to improve bus punctuality and regularity (Papageorgiou et al., 2006). SCOOT is able to provide differential bus priority if required by recalling, skipping or extending stages to ensure bus priority is given (Gardner et al., 2009).

SCOOT is able to follow trends over time in traffic flow and local short term changes; however, as the optimisation procedure only allows a small amount of change to split, cycle and offset times, then SCOOT could be constrained by this during a sudden change in flow (for example, a football match). However, a study in Toronto showed that SCOOT reduced delays after a baseball game by $61 \%$ in comparison with the previous fixed time plans (Quan et al., 1993).

\subsubsection{Sydney Coordinated Adaptive Traffic System (SCATS)}

SCATS works on a combination of coordinated vehicle actuation and fixed time plans as it uses a library of fixed time plans which have been developed to work in specific scenarios. It operates at two basic levels; the "upper level" which involves offset plan selection and the "lower level" which involves the optimisation of various junction parameters (Papageorgiou et al., 2006), such as split and cycle times (SCATS, 2012).

SCATS operates in real time and has many distributed controllers however it does not use fully comprehensive plans, it uses many smaller libraries of offsets and phase split plans. SCATS relies on incremental feedback from detectors to change the signal plans over time. There is a central control override for local junctions to implement incremental split plans which make $2 \%$ adjustment to the previous traffic signal phases. A critical intersection must be named for each of the regions which the surrounding junction plans is based on. The ratio of detected flow to saturated flow is determined in each region to assess the congestion levels. (Martin, 2001).

SCATS determines offsets through "marriages and divorces"; a library of external offset options are used and a marriage is where two adjacent regions adopt the same common cycle time. Internal offsets are driven by cycle length and can be adjusted by an engineer (Martin, 2001). SCATS is able to change cycle time after every cycle if the road conditions have changed sufficiently.

SCATS is able to provide priority for buses and trams through a three tiered system (high, medium and low). Trams can expect to receive high priority, which results in 
stages being skipped to prevent trams stopping, whereas buses would typically get medium priority which involves shortened or extended stages to reduce the number of stops (Gardner et al., 2009).

SCATS biggest performance weakness is the optimisation of its offsets, which has an impact on the progression of vehicles between regions, SCATS is based on stop line detection which means that there is no concept of how long the queue is (Martin, 2001). SCATS does however have a useful oversaturation feature; as the road reaches saturation flow then SCATS gives all of the extra cycle time to the busiest phase to reduce the impacts of congestion. Consequently SCATS is very good at coping with heavy flows which are close to saturation, complex flow patterns and unpredictable variations (Martin, 2001).

\subsubsection{Urban Traffic OPtimization by Integrated Automation (UTOPIA)}

UTOPIA is a hierarchical-decentralised traffic signal control strategy. It aims to minimise the total time lost by vehicles, however public vehicles are prioritised so that they are not stopped at signalised junctions. UTOPIA is based on an optimising cost function depending upon vehicle delays and stops, delays to public transport and deviation from reference plan and historical signal timings. Optimisation is applied to both the local and network level; the local level determines the signal timings based on the cost function and it is optimised for a 120 second time horizon (repeated every three seconds). At the network level, the cost function considers neighbouring intersections to build a dynamic signal co-ordination (Gardner et al., 2009).

UTOPIA has a three tiered hierarchical architectural system:

- Local Level - applies a microscopic model to estimate the state of the intersection directly collecting the measurements which characterises the junction (saturation flows, turning percentages, delays)

- Area Level - less detailed traffic model to monitor the state of the whole controlled network. This level validates the local detection, checking changes in the traffic data compared with historical data

- Town Supervisor Level - integrates the congestion information given by UTOPIA with data from other systems, such as bus travel times. A macroscopic model is used at this level, which has the advantage of collecting different sources of information and having coverage of the whole city (Hounsell et al., 2001)

UTOPIA has been explicitly designed with public transport priority in mind (KonSULT, 2009); consequently UTOPIA is combined with System for Priority and Optimisation of Traffic (SPOT) which provides bus priority through shifting the 'green window' to coincide with the anticipated arrival time of buses. Bus location technology is used far upstream of signalised junctions and the system can gradually adapt the junctions to match the arrival times. UTOPIA uses loop detectors at key locations in the network which are just downstream of the previous junction (Gardner et al., 2009).

UTOPIA in Turin had a significant impact on journey time as it resulted in reductions of $20 \%$ for public transport vehicle journey times and 10-15\% for other vehicles 
(Papageorgiou et al., 2006). UTOPIA appears to be more adaptive throughout the network, but the cost function has a lot of uncertainty associated with it, it would require regular maintenance to ensure sufficient efficiency. UTOPIA is fairly dependent on accurate journey time forecasting and detection technology so that priority can be given to public transport (Gardner et al., 2009).

\subsubsection{Real-time Hierarchical Optimized Distributed and Effective System} (RHODES)

Similar to UTOPIA, RHODES architecture is based on a three tiered hierarchy: the highest level assigns traffic to the network to determine base levels of traffic, this takes into account evolving traffic demand and network geometry. The level below is based on predicted platoon arrival patterns to determine signal timings. Finally, at the junction level the movements of individual movements are modelled.

RHODES responds to the natural stochastic behaviour of traffic (Gardner et al., 2009). There are two significant processes: 'estimation and prediction' and the 'decision system' process. The first stage is based on actual upstream data collected, and the second stage is where the split and cycle times are selected to optimise the given objective (minimal queue length, delay per vehicle or number of stops) (Papageorgiou et al., 2006).

\subsubsection{Method for the Optimization of Traffic signals In Online controlled} Networks (MOTION)

MOTION has two main components, MOTION Central and MOTION Local. The central function creates plans which can then be adjusted by the local element (Gardner et al., 2009). MOTION operates on four different functional levels (Hounsell et al., 2001):

(1) Data acquisition - this is used for different functions: network incident detection and for origins and destinations.

(2) Dynamic traffic model - through estimation of the most important individual traffic streams and analysis of traffic by determination of current traffic status.

(3) Optimizing control variables - iterations of common cycle times and split times are carried out to determine the optimum green times. The platoon model is used to try and optimise the offset timings between junctions.

(4) Decision - the new signal programs are compared to the current signal program. If there are major improvements then the signals are changed, however, if only minor improvements then the current signals are not changed.

MOTION does consider both the local and network levels; however, it is unclear how much the local plans can change the more strategic network plan. 


\subsubsection{Worldwide UTC Systems}

There are many UTC systems worldwide which are not widely discussed in the literature but are significant improvements on fixed time systems. The UTC system in Singapore is Green Link Determining (GLIDE), and it is a dynamic system which optimises green time for every approach. GLIDE has increased the average journey speeds by $8 \%$ in morning peak against fixed time systems (Keong, 1993).

The Japanese UTC system is Universal Traffic Management System (UTMS) and it uses infra-red technology to detect and communicate with the vehicles. Therefore UTMS is able to re-route drivers if they have an infra-red device installed in the car, as was shown in the Nagano Winter Olympics where drivers with the infra-red device could arrive at the destination up to $11 \%$ faster than drivers without (Kitamura, 1998).

\subsection{Discussion and Conclusion for UTC Systems}

The most challenging problem of comparing UTC systems, both directly and in relation to their fit to policy drivers, is that there are very few field studies with two commercial systems directly compared. When looking at published statistics from the designer, there will always be an element of bias due to the commercial nature of the product. Every city is different and has different requirements due to varying policies within countries, and policies change over time; for example environmental policies in many countries encourage the use of public transport and bicycles over private motor vehicles, whereas this may not be the case in other countries. Therefore choosing a UTC system is a specialised task; with Hounsell et al. (2001) highlighting some of the reasons why a Local Authority may choose one UTC system over another, reasons which must reflect both the policy and technology issues involved in the decision:

- National standards or preferences

- Expertise or available support for the system

- Robust demonstrations of its effectiveness in similar operating situations

- Implementation, operating and maintenance costs

- Traffic characteristics (traffic mix, growth, variability, level of congestion)

- Issues surrounding detector dependent systems (cost of maintenance)

- Prospects for future development

As growth in a town or city occurs, typically fixed time signals have been replaced by some form of UTC system to improve the efficiency of the network. However, as fixed time signals have been replaced, it was observed by Transportation Research Board (TRB), that UTC systems are considered much more operationally demanding than fixed time systems because of the additional technical expertise required to operate them (NCHRP, 2010). 
Table II: Summary of advantages and disadvantages of different types of UTC system (After: Papageorgiou et al., 2006)

\begin{tabular}{|c|c|c|c|}
\hline 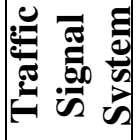 & Advantages & Disadvantages & Technology \\
\hline 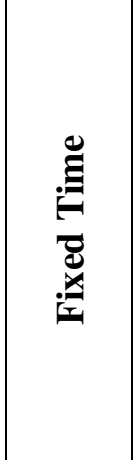 & $\begin{array}{l}\text { 1) Cheaper to install and } \\
\text { maintain } \\
\text { 2) Can be implemented } \\
\text { using non-centrally } \\
\text { controlled equipment } \\
\text { 3) Familiarity with } \\
\text { settings for regular users } \\
\text { 4) Green Waves more } \\
\text { easily implemented }\end{array}$ & $\begin{array}{l}\text { 1) Large amount of data to } \\
\text { be collected and updated } \\
\text { 2) Signal plans will require } \\
\text { updating } \\
\text { 3) Disruption caused when } \\
\text { plans change } \\
\text { 4) Operator needs to } \\
\text { respond to incidents } \\
\text { 5) Cannot deal with short } \\
\text { term traffic fluctuations }\end{array}$ & $\begin{array}{l}\text { Sensing: Offline } \\
\text { Communications: } \\
\text { None }\end{array}$ \\
\hline 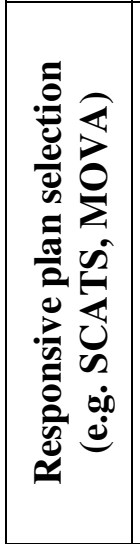 & $\begin{array}{l}\text { 1) Can deal with some } \\
\text { day to day fluctuations } \\
\text { 2) Could benefit arterial } \\
\text { routes more } \\
\text { 3) Cheaper than fully } \\
\text { responsive systems }\end{array}$ & $\begin{array}{l}\text { 1) Require more data than } \\
\text { fixed time } \\
\text { 2) Detector failures can } \\
\text { cause problems } \\
\text { 3) Discussions are } \\
\text { required on when to } \\
\text { change a plan } \\
\text { 4) The plan could change } \\
\text { for a wrong reason if } \\
\text { automated } \\
\text { 5) Difficult to foresee all } \\
\text { eventualities }\end{array}$ & $\begin{array}{l}\text { Sensing: Current } \\
\text { road state } \\
\text { Communications: } \\
\text { System } \\
\text { Dependent }\end{array}$ \\
\hline 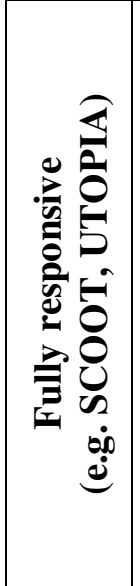 & $\begin{array}{l}\text { 1) Less data required in } \\
\text { advance } \\
\text { 2) Plan evolves with } \\
\text { time so no updating } \\
\text { required } \\
\text { 3) Can deal with short } \\
\text { and long term } \\
\text { fluctuations (better at } \\
\text { long) } \\
\text { 4) Automatic reaction to } \\
\text { incidents traffic } \\
\text { 5) Live } \\
\text { information available }\end{array}$ & $\begin{array}{l}\text { 1) Detector failure can } \\
\text { cause significant loss of } \\
\text { efficiency } \\
\text { 2) More expensive to } \\
\text { install, comparable for } \\
\text { maintenance } \\
\text { 3) Requires some central } \\
\text { control } \\
\text { 4) Maintenance is critical }\end{array}$ & $\begin{array}{l}\text { Sensing: Current } \\
\text { Road State } \\
\text { Communications: } \\
\text { Minimum of local } \\
\text { level }\end{array}$ \\
\hline
\end{tabular}

UTC systems clearly have substantial benefits over fixed time systems; however in a survey that was carried out by the TRB, UTC operators appeared to believe that they were often not given sufficient time or training to learn how to fully operate the systems (NCHRP, 2010). This is a significant problem for the efficiency of UTC systems if the operators do not understand how they work and emphasises that as technology has become more advanced the additional consideration of implementing and operating the 
technology has also grown in prominence. Table II indicates the advantages and disadvantages of the three different types of control system; it also shows the requirements of detection and communication technologies. As there are no direct comparisons of UTC systems, it is impossible to state objectively which system is best; however using Table II it is possible to identify the strengths and weaknesses of different systems and select a system based on the requirements.

The UTC systems which have been described in this section have been shaped by the technology available. Currently the UTC systems only have snapshots of the traffic state on the road due to the detection technologies used (inductive loops, infra-red, microwave). For UTC systems to improve beyond current limitations a better understanding of the road state is required and this can only occur through advances in detection and communication technologies which provide improved spatial and temporal data sources.

\subsection{PHASE 5 - Integrated UTC \& Intelligent Transport Systems [1997 - present]}

The most advanced urban traffic control systems are now becoming more centrally integrated with other traffic management systems to reduce the workload of network operators and to improve the efficiency of the network. There are many different elements to consider when managing traffic control (see Figure 1), and through effective integration the operator involvement can be reduced. This has been enabled through a number of technological advances; most of which are either improvements in detection techniques or methods of communicating with drivers.

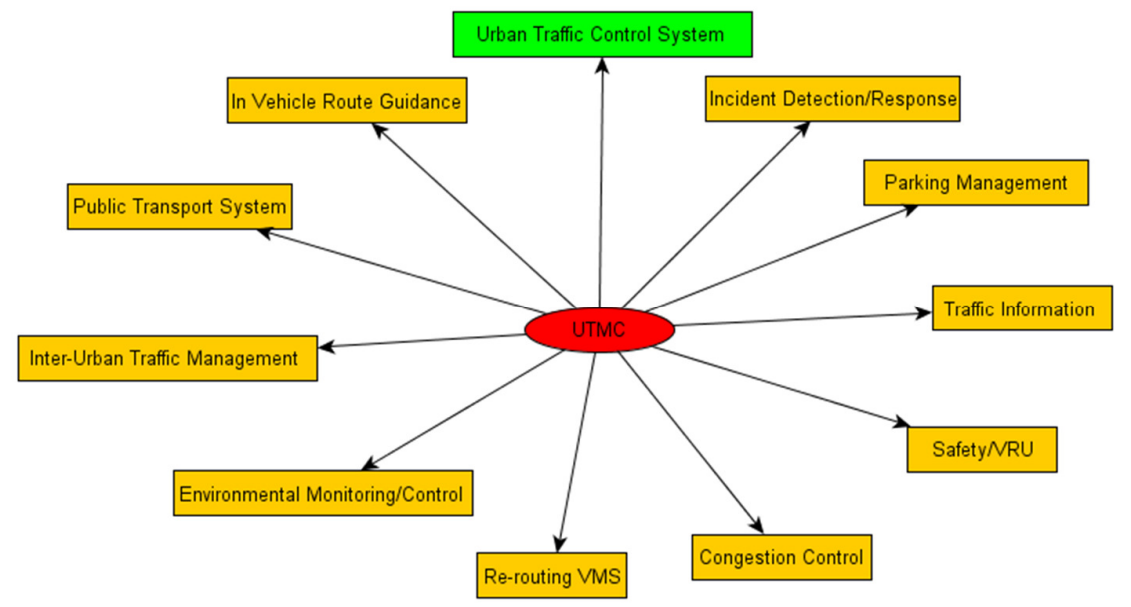

Figure 1: Schematic Illustration of a UTMC system (after DETR, 1999)

\subsubsection{Urban Traffic Management and Control (UTMC) Systems}

UTMC was a UK Department for Transport initiative to help local authorities obtain the most from their combined UTC system and Intelligent Transport Systems (ITS). UTMC systems are designed to allow different applications used within traffic management systems to communicate and share information with each other (DfT, 2009). This helps 
to build a more dynamic, intelligent and real-time information based traffic management system. Transport policy in the UK during the 1990's had targets of (Glaister, 2001):

- A safe and efficient transport system

- A better, more integrated public transport system

- A more environmentally sustainable transport system

- Better and more strategic integration of transport and land use planning

These targets were fairly generic but it is clear that integration was crucial to the policy of this era, and this was exactly the aim of UTMC.

Fundamentally UTMC systems are considered as modular, open systems which incorporate and build on existing functionalities of current signal control and other traffic management systems (Papageorgiou et al., 2006). The UTC system is at the heart of a UTMC system; however the other features add significant benefits by providing additional information about the network. Accurate and up to date information is critical for a successful UTMC system; for example, the operators can inform road users of congestion or accidents in the network and re-route them accordingly, or inform motorists of available parking facilities in a city centre. UTMC systems are built-up of many Intelligent Transport Systems, see Figure 1.

UTMC has many advantages for the road user (UTMC, 2009):

- Advise - the system can advise motorists on journey times, for example, using Automatic Number Plate Recognition cameras, the average speed can be determined and journey length displayed on Variable Messaging Signs (VMS).

- Warn - motorists can be warned of dangers on the network using VMS. 'Strong wind' messages can be displayed on bridges to warn motorists.

- Guide - motorists can be informed of delays on the road due to congestion or an accident using VMS. Also many cities use car park VMS upon entering city centre so that motorists can plan which car park to use.

A major benefit for the operators of UTMC is that national standards were created so that communication between ITS features would become easier. Standardisation was a policy led approach to deal with the issues of complex interactions between initially separate UTC and ITS systems, but this also enables a wider, and potentially cheaper, selection of products for local authorities (UTMC, 2009). A common language was developed to share information much faster, and therefore the transport network can utilise other forms of communication without paying the high installation costs, for example, the cable TV network can be used to send information (UTMC, 2009). The cost of running individual ITS were higher as individual detectors and communication devices were required, whereas detectors can now be used for more than one purpose. A shift to an all-inclusive traffic control system has created a more competitive market, with a wider choice of systems and suppliers. The interoperability of data is now much easier due to a standard format within UTMC systems, which is essentially a common database, and now there are systems such as CUTLAS or Comet which manage the data from various UTC and ITC sources to try to gain operational advantage (Envitia Plc., 2012)(Siemens, 2012). 
The United States also developed a very similar system called the National Transportation Communications in ITS Protocol (NTCIP) which focuses on a family of standards which have been designed in order to communicate effectively between computers and ITS components (AASHTO, 2009).

\section{The Future}

The continued policy desire to enable sustainable mobility is unlikely to change in the near future, with the key drivers remaining lower costs and lower environmental impacts. This section will show that the near future of urban traffic control will be shaped by the advances in technology which are likely to be implemented relatively soon into the transport industry. However it is imperative for policy measures to maintain pace with technology or infiltration rates of technologies will be much slower, and have less effect on network performance. With improved integration of technology into traffic control:

"[For the commuter] intelligently connected transport networks mean better travel information, fewer delays and less stress; [for the environment] it means fewer emissions" (Siemens, 2010).

\subsection{What technologies are likely to be used in the near future?}

Detection technologies are steadily improving and many new technologies have been tested in a European funded project called Cooperative Vehicle-Infrastructure Systems (CVIS). This project has researched and developed a new communications architecture which enables vehicles to communicate with one another and the surrounding infrastructure. The medium of communicating is through WLAN, infrared, cellular (GPRS/UTMS) or digital broadcast communication (CVIS, 2010a), enabling the greatest potential for adoption. Trials using the CVIS architecture and traffic control system have suggested that vehicles could save approximately $15 \%$ on travel time, and minor road traffic could save up to five seconds per vehicle per junction (CVIS, 2010a).

New communications technology will have a significant impact on urban traffic control systems in the near future. Through accurate detection and communication technology, vehicles can be located within the network quickly and their velocities known. This could help to improve the platoon dispersion modelling algorithms used so that the level of uncertainty is reduced. There is great potential for research in this area as more information and data sources becomes available to the operator. Also, if vehicles communicate between one another and there is heavy congestion, this information can be passed upstream of the incident rapidly. The EU project COOPERS used a driving simulator to demonstrate that drivers change their driving behaviour when advanced warning is given of severe driving conditions, and the driver's average speed dropped by $14 \%$ (COOPERS, 2010). Therefore by using this information, incoming vehicles could avoid joining queues or entering congested areas; hence improving the state of the network. 
The 'internet of things' is another methodology with which vehicles will be able to send and receive data. Individual vehicles have unique identities and act as messaging systems in which other vehicles, pedestrians and UTC operators will be able to read data sent from the vehicle. This could be where they have been, where they are going, what the weather was like in the previous road section and many other characteristics which may be of use (EPoSS, 2008).

Bluetooth sensors are becoming more popular for journey time estimation and there have been tests by Transport for London to find out if Bluetooth could be used to send information to drivers along key urban routes (TfL, 2006). One of the problems with Bluetooth sensors is that there is no certainty of the infiltration rate within vehicles which makes it inadequate for determining flow, however it does provide good speed and presence detection data (ITS, 2011a).

Floating vehicle data is a detection technique likely to be used more in the near future as it has already been tested (e.g. by ITIS Holdings plc and OPTUS (PR Newswire, 2009)). This is where active mobile phones can be used as traffic sensors; the location and velocity of the vehicle can be inferred which informs the network operators of the road condition. One of the most beneficial aspects of this technology is that no extra hardware is required through the network; however a new architecture would need to be developed to incorporate the new source of information into the traffic controls, as the current systems use a single detector point as opposed to a continuous data stream. Currently it is quite difficult to calibrate and validate UTC systems, but when floating vehicle data is used, it becomes easier due to the simplicity of data collection (CVIS, 2010b).

A recent example of how a non-government commercial innovation can be applied to a higher level transport system is Google's Google Map. Since 2007 Google Maps have displayed live traffic information for users who planned their route before travelling. This uses crowd-sourced data to gather anonymous location and velocity data to estimate the road conditions (Barth, 2009). Google then processes the information to output a visualisation of how congested or 'free flowing' the road was (although during the summer of 2011 the feature was briefly removed as Google themselves believed it to be "too inaccurate" (Schwartz, 2011)).

One of the largest problems with the location technologies described here are privacy issues regarding the information gathered from mobile phones or satellite navigation systems (Leduc, 2008). The data collected is made anonymous before being used to describe the road condition; however the general public may not believe this or understand the reasons behind collecting the information (Cruickshanks and Waterson, 2010). Members of the public want to know what data is being collected; can it be traced back to individuals, why do the transport authorities need it and can fines be issued because of this data? These questions need to be addressed so that the public can feel reassured that their privacy is not breached in any way.

Currently, variable messaging signs are the main method of conveying network information to the driver. However as live traffic feeds for satellite navigation systems becomes more commonplace, the operator can inform the motorist of any delays and reroute the vehicles through in-vehicle technologies. According to the CVIS project, the future ideal ITS needs a communication sub system which: (CVIS, 2010c) 
- Is available wherever and whenever a vehicle is present in a traffic situation

- Can communicate vehicle-vehicle and vehicle-infrastructure in a transparent way

- Relieves the application from the need to know about communication setup and management

- Uses modern Internet techniques and standards for global usability (IPv6)

- Provides a range of different possibilities related to data speeds, communication distance, cost and many other parameters

\subsection{PHASE 6 - Automated Urban Traffic Management \& Control}

If the technological trend (and policy cost drivers) toward continually reducing the need for human input into UTC systems continues, the logical conclusion will be a future where UTC is based around more intuitive systems which run without human assistance, but can highlight any issues within the system to the control centre. These automated systems should be able to manage the UTC system and ITS technologies efficiently to reduce human error during operation. An advantage of having a fully automated system would be the reduced costs, both labour costs and maintenance costs would be lower with less hardware in the road (inductive loops, infrared sensors) using detection technologies such as Floating Vehicle Data and satellite navigation systems as they are based on existing hardware.

With an intelligent automated system, the computer could learn over time how best to control the traffic signals if it were to monitor the average delay per vehicle. This type of control system has been developed and is based on Logistic Regression and Neural Networks. This automated method proved to outperform MOVA in simulation modelling but is yet to be tested on a real network (Box and Waterson, 2012).

While fully automated systems clearly have advantages, it is not anticipated that humans will be completely removed in the near future. As described above, current UTC systems are unable to take a holistic view and pre-empt large traffic flows. Events such as football matches can cause considerable trouble for the surrounding traffic control systems if strategies are not created to deal with the impending large flows. Due to the nature of sudden increases in traffic flow, UTC systems will always require some human input to update the time of these events.

Current UTC systems have also been shown to have a weakness in that they have to divide the network into smaller 'regions'. While coordination within a region is well established, the boundaries between regions will become more critical as traffic growth continues. New technology should be able to improve the communication between all junctions as better location technology and continuous communication will help to develop a more detailed picture of the upstream road state. The challenge associated with this problem is developing the control algorithms which can use the new data effectively.

When a holistic view of traffic management is taken, individual junction efficiencies can suffer to improve the state of the network as a whole. This is used in the concept of gating, where minor roads are intentionally delayed to maintain higher flow rates and 
more reliable journey times on the major route; for example, gating is going to be used at the 2012 London Olympics to improve journey time reliability along key corridor routes (SCOOT, 2008). If the control system was automated then it may recognise flow breakdown much quicker than a human, so it could prioritise major roads to reduce the lost time overall. When road conditions are approaching saturated flow then it would most likely be beneficial to prioritise the major roads at junctions to maintain free flowing traffic for as long as possible. This could cause significant delays to a small number of motorists though, which might be perceived as unfair, even though it should improve the state of the road for the remainder of their journey.

\subsection{Information Abundance}

If new technologies, such as floating vehicle data and vehicle to vehicle communications, are used in the near future to help coordinate traffic control, then there will be a paradigm shift from an era where there was a lack of information available to the UTC operator, to an era with an abundance of data. Currently there is a limited amount of data available through traditional sensors (inductive loops, infra-red, microwave detectors), and operators would like to know more information about the network, whether it be journey time data through automatic number plate recognition cameras or more CCTV cameras. However, if all of the potential new technologies are implemented then an increase in operational resources would need to be allocated to interpret the data, or else the extra information could become a wasted, and expensive, resource.

UTC is currently considering the use of technologies which were not specifically designed for it (ITS, 2011a); for example Wi-Fi has a dedicated bandwidth in Europe for transport but Wi-Fi was not designed with UTC in mind. Cellular data is now available for estimating journey times, and 'apps' have now been developed based on the very high infiltration rates of smartphones which can display the current state of the network through crowd-sourced data. Satellite navigation systems were not developed with the intention of providing crowd-sourced data for traffic control. However, the fact that UTC is moving in the direction of using technology which was not specifically developed for it can be seen as a result of financial-style policies, and by using these cheaper methods, which do not require any additional infrastructure on the road, then perhaps policy should enforce these more cost effective methods.

Before new policies can be implemented, the technologies must be assessed using a Cost Benefit Analysis tool (DfT, 2011). Benefits are typically measured in the form of vehicle hours saved, willingness to pay and the reduced maintenance costs (if any), whereas some of the costs will be the initial outlay and operational costs. Throughout this paper, policy has been shown to reduce costs through implementing new technology but money is not the only influencing factor. There is a real challenge involved with trying to quantify other benefits, but the 'willingness to pay' value is widely accepted within the industry (SafetyNet, 2009); however as monetary valuations on issues such as road safety are subjective, then a sensitivity analysis needs to be carried out before deciding on whether a project is worthwhile. 
The dissemination of information is also changing within the transport industry; it's not only local authorities who have to collect and disseminate information now. Social networking is having an impact on the way in which people travel, and it is an easy way to share traffic information with the general public. Many local authorities have Twitter and Facebook accounts so that they can pass on useful information to the local residents and visitors. Also with the increase of smart phones, there are 'apps' available to update the user of congestion so that they can use other routes (ITS, 2011b). Although it is still in its infancy as an industry, commercial travel information dissemination (i.e. not directly from local authorities) is also increasing, especially through increasing development and use of real-time data feeds for in-vehicle navigation systems.

\section{Conclusion}

Urban traffic control has evolved significantly due to continually facilitating technological improvements which has been encouraged by the policies implemented. The current coordinated UTC systems however are still limited by the availability of data and there are many technologies which are likely to be introduced in the near future which could improve detection techniques to shift the balance to an abundance of data. At present, UTC systems do not generate sufficient feedback from the data they have and therefore minimal attempts are made to continually improve the configuration (operator's discretion). A strategic view of the entire urban network, with improved detection and communication technologies, is required to enter the next evolution of urban traffic control.

A recent policy change which should have a serious impact on UTC is the European Union 2011 white paper which is advocating zero carbon emissions from transport in urban centres by 2050 (European Commission, 2011). This may provide the beginnings of the policy impetus necessary to begin the process of change. A potential change in the way UTC systems make decisions could be to minimise carbon emissions at every junction; which would be a significant change in ethos.

The detection and communication technologies required (Wi-Fi, Bluetooth, cellular data, vehicle to vehicle communications) to support this next phase are readily available now, but the infrastructure and architecture required to support them is not in place. Large investments are required to implement such systems (especially a move from infrastructure based to vehicle based detection) and this is the key block to achieving the next generation of UTC systems. Transport policy therefore needs to be changed to accommodate these new technologies into the transport network, but unfortunately there may be very long lead times (years or even decades) before the changes come into full effect (Eddington Report, 2006). This is the first time in UTC history where policy has not been the driver for the next stage; and until the implications of the EU White paper are incorporated into policy, it will continue to be new technologies, which were not specifically designed for UTC, driving policy.

The challenge will then be how to create a more integrated, intuitive control system which requires minimal human input. New technologies will help to develop a better understanding of where vehicles are, and where they are going, however, the current UTC systems have no way of using this new information. Innovative control algorithms will need to be developed to utilise the new data sources and help us to take the next step of the UTC evolutionary chain. 
American Association of State Highway and Transportation Officials (AASHTO), 2009. National Transportation Communications for ITS Protocol: The NTCIP Guide [Online]. Available at: www.ntcip.org/library/documents/pdf/9001v0406r.pdf [Last Accessed $14^{\text {th }}$ September 2012]

Barth, D., 2009. The bright side of sitting in traffic: Crowdsourcing road congestion data [Online]. Available at: http://googleblog.blogspot.com/2009/08/bright-side-ofsitting-in-traffic.html [Last Accessed $14^{\text {th }}$ September 2011]

BBC, 2009. The man who gave us traffic lights [Online]. Available at: www.bbc.co.uk/nottingham/content/articles/2009/07/16/john_peake_knight_traffic_ligh ts_feature.shtml [Last Accessed $14^{\text {th }}$ September 2012]

Bell, M. C., Bretherton, R. D., 1986. Ageing of Fixed-Time Traffic Signal Plans. Second International Conference on Road Traffic Control, 15-18 April 1986. London: IEE.

Bloomberg (Carol Wolf), 2011. Traffic Cost U.S. \$114.8 Billion in 2009, Texas Institute Says [Online]. Available at: www.bloomberg.com/news/2011-01-20/traffic-jams-cost-us-114-8-billion-in-time-fuel-in-09-institute-says.html [Last Accessed $14^{\text {th }}$ September 2012]

Box, S., Waterson, B., 2010. Signal Control using Vehicle Localization probe data [Online]. Available at: http://eprints.soton.ac.uk/73751/1/UTSG10BoxWaterson.pdf UTSG January 2010, Plymouth

Box, S., Waterson, B., (2012). An automated signalized junction controller that learns strategies from a human expert. Engineering Applications of Artificial Intelligence 25(1), 107-118, doi:10.1016/j.engappai.2011.09.008

Buchanan, C., D., 1964. Britain's Road Problem. The Geographical Journal, Vol. 130, No. 4, (Dec., 1964), pp.470-478 Available at: www.jstor.org/stable/1792258 [Last Accessed $14^{\text {th }}$ September 2012]

Byungkyu, B., Chen, Y., 2010. Quantifying the benefits of coordinated actuated traffic signal systems: A case study [Online]. Available at: www.virginiadot.org/vtrc/main/online_reports/pdf/11-cr2.pdf [Last Accessed $14^{\text {th }}$ September 2012]

COOPERS, 2010. Project Presentation [Online]. Available at: www.coopersip.eu/fileadmin/results/deliverables/D1A1100_COOPERS_Project_Presentation_052010.pdf [Last accessed $14^{\text {th }}$ September 2012]

Connery, R., H., Leach, R., H., 1960. The Federal Government and metropolitan areas. Cambridge: Harvard University Press.

Cruickshanks, S., Waterson, B., 2010 Are Privacy Fears Associated with Intelligent Transport Systems Justified? UTSG January 2011, Milton Keynes 
CVIS, 2010a. CVIS Mobility 2.0 - The New Cooperative Era. [Online]. Available at: www.cvisproject.org/download/ERT_CVIS_FinalProject_Bro_06_WEB.pdf [Last Accessed $14^{\text {th }}$ September 2012]

CVIS, 2010b. Cooperative Urban Mobility [Online]. Available at: www.cvisproject.org/download/CVIS Handbook FINAL\%20Version.pdf [Last Accessed $14^{\text {th }}$ September 2012]

CVIS, 2010c. CALM: Communication Access for Land Mobiles, CVIS 2.0: The Future of Intelligent Transport Systems [Online] Available at: www.cvisproject.org/download/qfree_cvis_brosjyre.pdf [Last Accessed $14^{\text {th }}$ September 2012]

Day, L., McNeil, I., 1996. Biographical dictionary of the history of technology. London: Routledge.

Department of the UK Environment, Transport and the Regions (DETR), 1999. The 'SCOOT' urban traffic control system. Traffic Advisory Leaflet 7/99, London, UK.

Department for Transport, 2009. The UTMC Initiative [Online]. Available at: www.utmc.uk.com/background/02.php [Last Accessed 14 ${ }^{\text {th }}$ September 2012]

Department for Transport, 2010. Transport Statistics Great Britain: 2011 Roads and Traffic [Online]. Available at: assets.dft.gov.uk/statistics/releases/transport-statisticsgreat-britain-2011/roads-and-traffic-summary.pdf [Last Accessed $14^{\text {th }}$ September 2012]

Department for Transport, 2011. Cost Benefit Analysis [Online]. Available at: www.dft.gov.uk/webtag [Last accessed $14^{\text {th }}$ September 2012]

Department for Transport, 2012. Vehicle Licensing Statistics, Great Britain: Quarter 2 2012 Vehicles [Online]. Available at: assets.dft.gov.uk/statistics/releases/vls-q22012/vls-q2-2012.pdf [Last Accessed 14 ${ }^{\text {th }}$ September 2012]

Eddington, R., 2006. The Eddington Transport Study. Volume 2: Defining the Challenge. Crown Copyright. Available at: www.hm-treasury.gov.uk [Last Accessed $14^{\text {th }}$ September 2012]

Envitia Plc., 2012. Interoperability [Online]. Available at: www.envitia.com/sectors/sectordetails.aspx?id=17,628,0 [Last Accessed $14^{\text {th }}$ September 2012]

EPoSS, 2008. Internet of Things in 2020 [Online]. Available at: www.iotvisitthefuture.eu/fileadmin/documents/researchforeurope/270808_IoT_in 2020_Worksh op_Report V1-1.pdf [Last Accessed $14^{\text {th }}$ September 2012]

European Commission, 2011. White Paper on Transport [Online]. Available at: http://ec.europa.eu/transport/strategies/doc/2011_white_paper/white-paper-illustratedbrochure en.pdf [Last Accessed $14^{\text {th }}$ September 2012]

Gardner, K., D’Souza, C., Hounsell, N.B., Shrestha, B.P., Bretherton, D., 2009. Review of Bus Priority at Traffic Signals around the World. [Online]. Available at: www.trg.soton.ac.uk/research/bus/UITP_WORKING_GROUP_Interaction_of_buses_si 
gnals at road_crossings-FINAL_REPORT_V2.0-April_2009.pdf [Last accessed $14^{\text {th }}$ September 2012]

Glaister, S., 2001. UK Transport Policy 1997-2001 [Online]. Available at: www.cts.cv.ic.ac.uk/staff/wp21-glaister.pdf [Last accessed $14^{\text {th }}$ September 2012]

Hounsell, N., B., McDonald, M., 2001. Urban Network Traffic Control. Journal of Systems and Control Engineering, 215(4), pp.325-334.

Hounsell, N.B., Shrestha, B.P., Piao, J. and McDonald, M., 2009. Review of urban traffic management and the impacts of new vehicle technologies. Institution of Engineering \& Technology, Intelligent Transport Systems, 3, (4), 419-428. (doi:10.1049/iet-its.2009.0046)

Hunt, P., B., Robertson, D., I., Bretherton, R.D., Winton, R., I., 1981. SCOOT - $a$ traffic responsive method of coordinating signals [Online]. Available at:

www.trl.co.uk/online store/reports publications/trl_reports/cat traffic engineering/rep ort scoot - a traffic responsive method of coordinating signals.htm [Last accessed $14^{\text {th }}$ September 2012]

ITS, 2011a. Welcome to the jungle, ITS International, Vol. 17 (2), March/April 2011, pp 48-49. Kent: Route One Publishing Ltd.

ITS, 2011b. Traffic services booming from explosion of data, ITS International, Vol. 17 (6), November/December 2011, pp 51-52. Kent: Route One Publishing Ltd.

Jhaveri, C. S., Perrin, J., Jr., Martin, P. T., 2003. SCOOT Adaptive Signal Control: AN Evaluation of its Effectiveness over a Range of Congestion Intensities. TRB 2003 Annual Meeting, CD-ROM. Shoreham, January 2003.

Keong, C., K., 1993. The GLIDE System - Singapore's urban traffic control system. Transport Reviews: A Transnational Transdisciplinary Journal, Vol. 13 (4), pp. 295305

Kitamura, O., M., 1998. Overview of the UTMS on the Nagano Winter Olpympic Games. $5^{\text {th }}$ Annual World Congress on ITS, Seoul, $12^{\text {th }}-16^{\text {th }}$ October 1998.

KonSULT, 2009. Urban Traffic Control Systems [Online]. Available at: www.konsult.leeds.ac.uk/private/level2/instruments/instrument014/12_014c.htm [Last Accessed $14^{\text {th }}$ September 2012]

Leduc, G., 2008. Road Traffic Data: Collection methods and applications [Online]. Available at: http://ftp.jrc.es/EURdoc/JRC47967.TN.pdf [Last Accessed $14^{\text {th }}$ September 2012]

Marshproducts, 2000. The basics of loop vehicle detection [Online]. Available at: www.marshproducts.com/pdf/Inductive\%20Loop\%20Write\%20up.pdf [Last accessed $14^{\text {th }}$ September 2012]

Martin, P., 2001. SCATS, An Overview. Transportation Research Board Annual Meeting 2001. Available at: www.signalsystems.org.vt.edu/documents/Jan2001_AnnualMeeting/SCATS_TRB2001_ 
PeterMartin.pdf [Last Accessed 14 ${ }^{\text {th }}$ September 2012]

Ministry of Transport, Great Britain, 1966. Transport Policy (Cmnd 3057). London: HMSO

Ministry of Transport, Great Britain, 1969. Roads for the Future: a new inter-urban plan (Cmnd 4369). London: HMSO

Mueck, J., 2008. The German Approach to Adaptive Traffic Control. Siemens.

NCHRP, 2010. Adaptive Traffic Control Systems: Domestic and foreign State of Practice, (Synthesis 403), Washington, D.C.

Papageorgiou, M., Ben-Akiva, M., Bottom, J., Bovy, P. H. L., Hoogendoorn, S. P., Hounsell, N. B., Kotsialos, A., McDonald, M., 2006. ITS and Traffic Management. Handbooks in Operations Research and Management Science, Ch11 pp743-754.

Elsevier.

PR Newswire, 2009. Nationwide traffic system deployed in Australia using ITIS

TrafficScience CFVD technology [Online]. Available at: www.prnewswire.co.uk/newsreleases/nationwide-traffic-system-deployed-in-australia-using-itis-trafficsciencetmcellular-floating-vehicle-data-cfvd-technology-152765845.html [Last Accessed $14^{\text {th }}$ September 2012]

Quan, B. Y., Greenough, J. C., Kelman, W. L., 1993. The Metropolitan SCOOT Demonstration Project: Municipality of Metropolitan Toronto.

Robertson, D., I., 1982. Coordinating Traffic Signals to Reduce Fuel Consumption [Online]. Available at: www.jstor.org/stable/2397455 [Last Accessed $14^{\text {th }}$ September 2012]

Royal Commission on Transport, Great Britain, 1929. Control of traffic on roads: The First Report (Cmnd. 3365) London: HMSO

SafetyNet, 2009. Cost-Benefit Analysis [Online]. Available at: ec.europa.eu/transport/road_safety/specialist/knowledge/pdf/cost_benefit_analysis.pdf [Last accessed $14^{\text {th }}$ September 2012]

SCATS, 2012. Products: Adaptive Control [Online]. Available at: www.scats.com.au/product adaptive control.html [Last Accessed $14^{\text {th }}$ September 2012]

Schwartz, B., 2011. Google maps removes driving with traffic estimates [Online]. Available at: www.seroundtable.com/google-maps-traffic-13702.html [Last accessed $14^{\text {th }}$ September 2012]

SCOOT, 2008. SCOOT MMX Service Pack 1 [Online]. Available at: www.scootutc.com/SCOOTMMXSP1.php?menu=Versions [Last accessed $14^{\text {th }}$ September 2012]

Siemens, 2010. Traffic Solutions: Equipment, installation, maintenance and operation for traffic control [Online]. Available at: www.siemens.co.uk/careers/pool/apprenticeships/siemens-traffic-brochure.pdf [Last Accessed $14^{\text {th }}$ September 2012]. 
Siemens, 2012. Comet [Online]. Available at:

www.siemens.co.uk/traffic/en/index/productssolutionsservices/systems/comet.htm [Last accessed $14^{\text {th }}$ September 2012]

Skabardonis, A., 2001. ITS Benefits: The Case of Traffic Signal Control Systems.

Washington: District of Columbia 7-11 January 2001.

TfL, 2006. Transport for London's test of value added services to support DSRC road charging trials [Online]. Available at: www.tfl.gov.uk/assets/downloads/TfL-valueadded-test.pdf [Last Accessed 14 ${ }^{\text {th }}$ September 2012]

The Engineer, 1868. Street signals, Bridge street, Westminster [Online]. Available at: www.ukroads.org/ukroadsignals/articlespapers/18681211_theengineer.pdf [Last Accessed $14^{\text {th }}$ September 2012]

TRL, 2011. MOVA [Online]. Available at:

www.trlsoftware.co.uk/products/traffic control/mova [Last Accessed $14^{\text {th }}$ September 2012]

US Census Bureau, 2005. Trends in Vehicle Miles Travelled [Online]. Available at: www.pewclimate.org/global-warming-basics/facts_and_figures/us_emissions/vmt.cfm [Last Accessed $14^{\text {th }}$ September 2012]

U.S. Department for Transport, 2005. Signal Timing on a Shoestring (FHWA-HOP-07006) Available at:

www.cedengineering.com/upload/Signal\%20Timing\%20on\%20a\%20Shoestring.pdf [Last Accessed $14^{\text {th }}$ September 2012]

UTMC, 2009. FAQS [Online]. Available at: www.utmc.uk.com/background/pdf/UTMCFAQsBeginnerGuide.pdf [Last Accessed $14^{\text {th }}$ September 2012]

UTMC, 2009. Welcome to UTMC [Online]. Available at: www.utmc.uk.com [Last Accessed $14^{\text {th }}$ September 2012]

Wylie, M., 2009. Aimsun to Siemens SCOOTLINK Application [Online]. Available at: www.ukroads.org/ukroadsignals/articlespapers/20090923_Martin_WylieAimsun_to_Siemens_SCOOT_Link.pdf [Last Accessed $14^{\text {th }}$ September 2012] 